Turkish Journal of Geriatrics

DOI: 10.31086/tijgeri.2020.143

2020; 23(1): 100-107

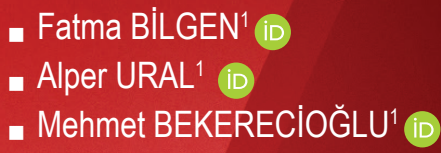

CORRESPONDANCE

Fatma BiLGEN

Kahramanmaras Sutcu Imam University,

Plastic Rekonstructive and AestheticSurgery,

Kahramanmaraş, TURKEY.

Phone: +905057280165

e-mail: fatmabilgen81@gmail.com

Received: 20/05/2019

Accepted: 25/02/2020

${ }^{1}$ Kahramanmaras Sutcu Imam University,

Plastic Rekonstructive and AestheticSurgery,

Kahramanmaraş, TURKEY.

\section{EVALUATION OF POSTOPERATIVE COMPLICATIONS IN ELDERLY PATIENTS UNDERGOING PLASTIC SURGERY ACCORDING TO THE MODIFED CLAVIEN-DINDO CLASSIFICATION}

\section{Abstract}

Aim: Although age is not encountered as a contraindication for surgery, performing the surgical procedures in shortest time possible is essential in order to avoid complications and facilitate management of the coexisting comorbidities. The aim of this study is to determine the complication rates and to evaluate the risk factors according to the modified Clavien Dindo classification in elderly patients over 80 years of age who received plastic and reconstructive surgery.

Material and Method: 184 patients over 80 years of age who were treated in the Plastic Reconstructive and Aesthetic Surgery Clinic between January 2015 and December 2018 were included in the study. The diseases were examined in five different groups consisting of acute or chronic wound (pressuresores, diabetic wounds, vascular trauma, trauma, etc.), malignant skin tumors, benign skin tumors, craniomaxillofacial trauma and others (hand trauma, temporamandibular joint dysfunction,etc.).

Results: When the complications were evaluated, it was observed that a total of 50 patients had medical or surgical complications. According to the Dindo Clavien classification, the most common complication was vascular compromise of flaps or wounds tha tnecessitated debridement application under local anesthesia in 17 patients with stage IIIA. The total complication rate was $27.1 \%$.

Conclusion: Age is not a contraindication for the elderly in cases when plastic surgery procedures should be performed. Evaluating comorbidities and the preoperative medical conditions delicately, choosing the appropriate anesthesia method and performing the shortest possible surgical procedure with the aim of shorten the duration of surgery is essential in order to reduce and prevent postoperative complications in elderly patients.

Keywords: Aged; Complication; Surgery. 


\section{INTRODUCTION}

Life expectancy is increasing worldwide as a result of the improvement in socioeconomic status as well as development of medical and surgical treatments. These demographic changes lead to increased proportions of old and elderly people in the general population.

Therefore, the applicability and number of surgeries considered to be risky in elderly patients are increasing. This can lead to impaired functional organ capacity in elderly patients and increased rates of complication $(1,2)$. Although age is not typically considered a contraindication for surgery, performing the surgical procedures in the shortest time possible is essential to avoid complications and facilitate management of coexisting comorbidities $(3,4)$.

The Clavien classification system is frequently used to provide standardization for patients to be informed of complications and for grading and evaluating complications. This classification was first established by Clavien et al. (5) in 1992 to evaluate complications of general surgical procedures. Because this classification system did not consider the duration of hospitalization and was insufficient in classifying life-threatening complications as well as evaluating permanent complications, it was modified by Dindo and Clavien (6) in 2004.

Finlayson and Birkmeyer retrospectively evaluated operative mortality in millions of patients aged 65-99 years who underwent major elective surgeries and found that the mortality rate increased with age and the surgical mortality rate in patients over 80 years was twice as high as that in patients aged 65-69 years (7).

To the best of our knowledge, there are no studies in the literature researching the complications and risk factors of elderly patients undergoing surgical interventions in the field of plastic surgery. This study aims to determine the complication rates and evaluate the risk factors according to the modified Clavien-Dindo classification in el- derly patients aged over 80 years who underwent plastic and reconstructive surgeries.

\section{MATERIALS AND METHOD}

After the approval of the local ethics committee, 184 patients over 80 years of age who were treated in the plastic reconstructive and esthetic surgery clinic between January 2015 and December 2018 were included in the study. Clinical data obtained from the hospital management information system and patient records involving age, gender, type of disease, laboratory parameters (hemoglobin, albumin, and white blood cell count), systemic diseases (hypertension, diabetes, pulmonary diseases, and cardiovascular diseases), treatment method (conservative or surgery), surgical procedure, anesthesia type, postoperative complications, and hospitalization period were retrospectively evaluated. Only the initial applications were considered in patients who had recurrent applications. The diseases were examined in five different groups consisting of acute or chronic wound (pressure sores, diabetic wounds, vascular trauma, trauma, etc.), malignant skin tumors, benign skin tumors, craniomaxillofacial trauma, and others (hand trauma, temporamandibular joint dysfunction, etc.).

The comorbidity status of the patients was evaluated utilizing the American Society of Anesthesiologist (ASA) performance status (PS). ASA PS is a scoring system used to describe the risk of anesthesia.

The laboratory parameters of the patients were taken into consideration in their first hospital visits, and abnormal values were controlled following consultations to the relevant departments during hospitalization. Conservative care was given predominantly to the patients in the wound group by means of dressings and vacuum-assisted closure (VAC) therapy. Surgical treatment was performed especially in skin tumor patients under local or general anesthesia as excision-primary repair as well as reconstruction with graft and/or flap ac- 
cording to tumor size and the resultant defect following tumor removal. Complication rates were evaluated according to the Clavien-Dindo classification (Table 1).

In the present study, according to the ClavienDindo classification, follow-up of the performed surgical procedure (flap circulation follow-up, wound care, hemorrhage, hematoma, etc.) was accepted as grade 1, while additional drug use for systemic diseases (hypertension, diabetes mellitus [DM], etc.) was accepted as grade 2. Surgical procedures performed under local anesthesia (e.g., wound debridement) were accepted as grade 3A, while surgical procedures performed under general anesthesia were accepted as grade 3B.

\section{Statistical methods}

All data were analyzed using the SPSS 24.0 statistical package program. Minimum, maximum, mean, and median values were calculated.

Fisher's exact test was used compare the complication rates between independent variables. Multiple logistic regression analysis was performed to evaluate the risk factors in postoperative complications. P? 0.05 values were considered as statistically significant. Odds ratios (ORs) and 95\% confidence intervals of the variables were determined.

\section{RESULTS}

One hundred and eighty-four patients over 80 years of age were included in the study. The mean age of the patients was 88 (80-99 years); 88 (47.82\%) were females, and 96 (52.17\%) were males. The mean hemoglobin value was calculated as 11.9 (8.3-16.4), while the mean white blood count value was 9.28 (3.77-60.28), and the mean value of albumin was 3.52 (1.2-4.9). Systemic diseases of the patients were also determined (Table 2). During the hospitalization period, the necessary departmental consultations were requested, and appropriate treatments were initiated subsequently.

According to the type of diseases, it was found that the highest number of patients were treated for malignant skin tumor (105 patients), followed by wounds (DM, peripheral vascular disease, pressure sore, and trauma), craniomaxillofacial traumas, benign skin tumors, and others (hand trauma, temporamandibular joint dysfunction, etc.) (Table 3). The majority of patients with malignant and benign skin tumors were treated by surgical intervention under local or general anesthesia, while wounded patients were treated with conventional dressings or VAC after debridement.

When the patients were evaluated according

Table 1. Clavien-Dindo classification.

\begin{tabular}{|l|l|}
\hline Grade & Complication \\
\hline 1 & $\begin{array}{l}\text { Any deviation from the normal postoperative course without the need for pharmacological treatment or } \\
\text { surgical, endoscopic, and radiological interventions }\end{array}$ \\
\hline 2 & Requiring pharmacological treatment with drugs other than those allowed for grade 1 complications \\
\hline $3 \mathrm{~A}$ & Requiring surgical, endoscopic, or radiological intervention not under general anesthesia \\
\hline $3 \mathrm{~B}$ & Requiring surgical, endoscopic, or radiological intervention under general anesthesia \\
\hline $4 \mathrm{~A}$ & Single-organ dysfunction (including dialysis) \\
\hline $4 \mathrm{~B}$ & Multiorgan dysfunction \\
\hline 5 & Death of a patient \\
\hline
\end{tabular}


Table 2. Patient characteristics.

\begin{tabular}{|l|r|}
\hline Patients & Number $(\mathbf{n}=184)$ \\
\hline Age (years) & \\
Mean & $88 \pm 2.34$ \\
Range (min-max) & $80-99$ \\
\hline Sex & \\
Female, $n$ (\%) & $88(47.8 \%)$ \\
Male, $\mathrm{n}(\%)$ & $96(52.1 \%)$ \\
\hline ASA PS & \\
$\leq 2, \mathrm{n}(\%)$ & $89(73.5 \%)$ \\
$\geq 3, \mathrm{n}(\%)$ & $32(26.4 \%)$ \\
\hline Hemoglobin (g/dL) & \\
Mean & $11.9 \pm 1.26$ \\
Range (min-max) & $8.3-16.4$ \\
\hline Leukocytes (white blood & \\
cells) ( $\mu \mathrm{L})$ & \\
Mean & $9.28 \pm 3.62$ \\
Range (min-max) & $3.77-60.28$ \\
\hline Albumin (g/dL) & \\
Mean & $3.52 \pm 1.35$ \\
Range (min-max) & $1.2-4.9$ \\
\hline Systemic Disease & 72 \\
Hypertension & 56 \\
Diabetes mellitus & 18 \\
Pulmonary disease & 68 \\
Cardiovascular disease & \\
\hline
\end{tabular}

Minimum: min, maximum: max

to treatment method, it was observed that 121 patients were treated surgically, while the other patients were followed with medical treatment or dressing. When surgical treatment methods were considered, primary repair after skin tumor excision was found to be the most frequent, followed by skin grafting, local flap, debridement, and fracture repair procedures.

Of the patients undergoing surgical treatment, 94 had local anesthesia, and 27 had undergone surgery under general anesthesia. Local anesthesia was mostly preferred since it is more appropriate for the prevention of complications due to
Table 3. Distribution of disease types.

\begin{tabular}{|l|r|}
\hline Disease & Number of Patients \\
\hline Malign skin tumor & 105 \\
\hline $\begin{array}{l}\text { Wound (diabetes } \\
\text { mellitus; pressure sore) }\end{array}$ & 56 \\
\hline Maxillofacial trauma & 5 \\
\hline Benign tumor & 6 \\
\hline Other & 12 \\
\hline Total & 184 \\
\hline
\end{tabular}

Table 4. Distribution of patients according to treatment modality, anesthesia type, and duration of surgery

\begin{tabular}{|l|r|}
\hline Patients & Number $(\mathbf{n})$ \\
\hline & \\
Treatment modality & \\
Surgery & 121 \\
Medical treatment/wound care & 63 \\
\hline Surgical Method & \\
Tumor excision + primary repair & 64 \\
Skin graft & 28 \\
Local flap & 13 \\
Debridement & 8 \\
Fracture repair & 3 \\
Amputation & 3 \\
Tendon repair & 2 \\
\hline Anesthesia type & \\
Local & 94 \\
General & 27 \\
\hline Operation duration (min) & \\
$<60$ & 80 \\
$\geq 60 ;<120$ & 32 \\
$\geq 120$ & 2 \\
\hline
\end{tabular}

existing systemic diseases in elderly patients. The operation length was mostly less than $60 \mathrm{~min}$, just as the operation length was longer than 120 min only in two patients (Table 4). 
Table 5. Complication distribution by the Dindo-Clavien classification

\begin{tabular}{|c|c|c|c|c|c|}
\hline \multirow{2}{*}{ Clavien-Dindo Grade } & \multicolumn{5}{|c|}{ Years } \\
\hline & 2015 & 2016 & 2017 & 2018 & Total \\
\hline 1 & 2 & 3 & 6 & 4 & 15 \\
\hline II & 2 & 3 & 3 & 2 & 10 \\
\hline IIIA & 1 & 7 & 6 & 3 & 17 \\
\hline IIIB & 1 & 3 & 2 & 2 & 8 \\
\hline Total & 6 & 16 & 17 & 11 & 50 \\
\hline
\end{tabular}

I-Flap follow-up: follow-up surgical procedure; II-Additional medical treatment following the performed surgical procedure besides systemic diseases such as diabetes and hypertension; IIIA—Additional surgery (wound debridement) under local anesthesia; IIIB-Wound debridement under general anesthesia; IV and V—not seen.

Table 6. Effect of Risk Factors on Complications.

\begin{tabular}{|c|c|c|}
\hline Risk Factors & $\begin{array}{r}\text { Complications (n:50) } \\
\% 27.1\end{array}$ & $\begin{array}{r}\text { Univariate } \\
\mathrm{p}\end{array}$ \\
\hline $\begin{array}{l}\text { Diabetes } \\
\text { Absent } \\
\text { Present } \\
\text { Pulmonary Disease } \\
\text { Absent } \\
\text { Present } \\
\text { Cardiovasculare Disease } \\
\quad \text { Absent } \\
\text { Present } \\
\text { Hypertension } \\
\text { Absent } \\
\text { Present } \\
\text { Type of Disease } \\
\text { Malign skin tumor } \\
\text { Wound (diabetes mellitus; pressure sore) } \\
\text { Maxillofacial trauma } \\
\text { Benign tumor } \\
\text { Other } \\
\text { Operating room time (min) } \\
<60 \\
\geq 60 ;<120 \\
\geq 120 \\
\text { ASA PS } \\
\leq 2 \\
\geq 3\end{array}$ & $\begin{array}{r}48(\% 36.9) \\
2(\% 3.70) \\
47(\% 28.31) \\
3(\% 5.55) \\
48(\% 41.37) \\
2(\% 2.94) \\
47(\% 40.17) \\
3(\% 4.16) \\
17(\% 16.1) \\
28(\% 50) \\
1(\% 25) \\
1(\% 16.6) \\
3(\% 25) \\
18(\% 22.5) \\
30(\% 93.75) \\
2(\% 100) \\
18(\% 20.2) \\
32(\% 100)\end{array}$ & $\begin{array}{l}=0.16 \\
=0.09 \\
=0.18 \\
=0.12\end{array}$ \\
\hline
\end{tabular}


Table 7. Risk Factors for Postoperative Complications.

\begin{tabular}{|l|r|r|r|}
\hline Variables & OR & $95 \% \mathrm{Cl}$ & p-values \\
\hline ASA PS & 1 (ref) & & \\
$\leq 2, \mathrm{n}(\%)$ & 2.64 & & 0.01 \\
$\geq 3, \mathrm{n}(\%)$ & 1 (ref) & & \\
\hline Operation duration (min) & 2.19 & & \\
$<60$ & 4.76 & $1.32-5.23$ & $<0.05$ \\
$\geq 60 ;<120$ & 1 (ref) & $1.90-8.79$ & \\
$\geq 120$ & 2.72 & & \\
\hline Types of disease & & & \\
Other & & & \\
Ulcer & & & \\
\hline
\end{tabular}

* Others: traumatic injuries, tumors, orscars ** Ulcers: PAD, pressure ulcers, necrotizing fasciitis, other ulcers (those associated with diabetes, collagen, radiation, etc.)

When the complications were evaluated, it was observed that a total of 50 patients had medical or surgical complications. According to the Dindo-Clavien classification, the most common complication was vascular compromise of the flaps or wounds that necessitated debridement application under local anesthesia in 17 patients with stage IIIA. Medical complications were observed in patients who underwent surgery lasted more than 60 min via general anesthesia and also in patients who received additional drug medication due to hypertension and cardiovascular disease (Table 5). The total complication rate was $27.1 \%$.

Surgical and medical complications were found to be related with ASA PS, duration of operation and type of disease. Increased complication rates were determined in patients with peripheral arterial disease, pressure ulcers, and other types of ulcers as well as patients whose ASA PS $\geq 3$, and duration of surgical operation was longer than 60 minutes. ( $P<0.05)$ (Table 6,7).

\section{DISCUSSION}

Compatible with that of the world, the elderly population in our country is also increasing. Ac- cording to recent researches in Turkey, from 2012 to 2016, the elderly population (aged 265 ) increased by $17.1 \%$, and the elderly population became $6,651,503$, while it was $5,682,003$ in 2012. It has been demonstrated that $60.3 \%$ of the elderly population were within the 65-74 age group, while $32.5 \%$ of the elderly were between 75 and 84 , and $7.1 \%$ of them were $\geq 85$ years old in 2012. The distribution of the elderly population in 2016 was as follows: $61.5 \%$ were between 65 and 74 years old, $30.2 \%$ were in the $75-84$ age group, and $8.2 \%$ were $\geq 85$ years old (8).

There is also an outstanding increase in diseases such as chronic ulcers and skin tumors related to aging. In order to improve the quality of life in patients with such disorders, hospitalization time and surgical operation rates are also increasing. Therefore, it is crucial to evaluate the risk factors for postoperative complications in elderly patients $(4,9)$.

Aging is characterized by progressive atrophy, fibrosis, and loss of elasticity in organs and tissues. Elderly patients have different characteristics in terms of physiological, pharmacological, psychological, and social aspects when compared to young patients $(9,10)$. Evers et al. emphasized that 
the effect of age on different organs and systems generally did not affect normal functions, and they also denoted that organs of the elderly met the basal needs when there is no chronic disease in the elderly concurrently with the decreased functional reserve capacity (11). In case of stress, elderly people cannot respond well enough. Surgery and anesthesia are also a source of stress. According to the American Society of Anesthesiologists classification, age alone is not a strong factor in the emergence of side effects due to anesthesia $(12,13)$. Age is a minor risk factor. Examination of comorbid diseases are mainly associated with age is essential (14). The most important factors affecting perioperative morbidity and mortality in the elderly are the presence comorbid diseases of the cardiovascular, pulmonary, endocrine, and neurological systems and presence of malnutrition as well as immune system disorders $(9,15)$. In this study, the vast majority of the patients had a history of at least one or more chronic diseases.

Nowadays, the rate of surgical interventions in the elderly population is increasing due to the development of surgical methods, operative techniques, and improved postoperative care. Meticulous preoperative assessment, individualized optimal surgical technique, and proper anesthetic method are crucial in geriatric surgery. To decrease anesthesia-related issues, preoperative evaluation, accurate assessment of existing comorbidities as well as the main surgical problem, and selection of the appropriate drugs and anesthetic method are gaining importance $(1,9,16)$. In our study, local anesthetics was administered in $51 \%$ of the patients by injection, while general anesthesia was used in $14.6 \%$.

Chung et al. reported that patients had fewer postoperative confusion and delirium after regional anesthesia in geriatric patients compared to those who had general anesthesia. Lower morbidity rates and less blood loss and postoperative thromboembolic complication rates have been reported after regional anesthesia (17). A decrease in perfusion of the skin and soft tissue in the elderly patients makes them more sensitive to pressure-induced ischemia. Reduction of cardiac and respiratory functions is further worsened by the cardiodepressive effect of inhaled drugs. Drug elimination is prolonged along with impaired liver and kidney functions. The sensitivity of the cerebral cortex to narcotic and hypnotics increases in advanced ages (18).

Fukui et al. has shown that the duration of operation has the strongest effect on the risk of complications in terms of both medical and surgical complications in elderly patients undergoing plastic surgery procedures. In addition, they reported that low serum albumin levels increased the frequency of complications, especially in patients with ulcers (pressure sores, PAD, necrotizing fasciitis, and diabetic ulcers), and they developed more frequent postoperative complications compared to other patients (19). In our study, it is seen that there was a significant relationship between the complication rates and the disease type, just as the correlation between the duration of surgical operation and ASA ps score.

According to the Dindo-Clavien classification, the most common complication was observed in 17 patients of grade III as impaired flap circulation necessitated debridement under local anesthesia. Moreover, patients who needed additional medical treatments were found to be composed of the ones who underwent operation via general anesthesia over $60 \mathrm{~min}$ and/or those having comorbidities.

As a result, age is not a contraindication for the elderly in cases when plastic surgery procedures should be performed. Evaluating comorbidities and the preoperative medical conditions delicately, choosing the appropriate anesthesia method, and performing the surgical procedure with the aim of shortening the duration of surgery are essential in order to reduce and prevent postoperative complications in elderly patients. 


\section{REFERENCES}

1. Alexander KP, Anstrom KJ, Muhlbaier $\mathrm{LH}$, et al. Outcomes of cardiac surgery in patients $\geq 80$ years: results from the National Cardiovascular Network. J Am CollCardiol 2000;35:731-8. (PMID: 10716477).

2. Klopfenstein CE, Herrmann FR, Michel JP, Clergue F, Forster $A$. The influence of an aging surgical population on the anesthesia workload: a ten-year survey. AnesthAnalg 1998;86:1165-70. (PMID:9620497).

3. Tahiri M, Sikder T, Maimon G, et al. The impact of postoperative complications on the recovery of elderly surgical patients. SurgEndosc 2016;30:176270. (PMID:26194260).

4. Sieber FE, Barnett SR. Preventing postoperative complicationsin the elderly. Anesthesiol Clin 2011;29:83-97 (PMID:91725754).

5. Clavien PA, Sanabria JR, Strasberg SM. Proposed classification of complications of surgery with examples of utility in cholecystectomy. Surgery 1992;111:518-26. (PMID:1598671).

6. Dindo D, Demartines N, Clavien PA. Classification of surgical complications: a new proposal with evaluation in a cohort of 6336 patients and results of a survey. AnnSurg 2004;240:205-13. (PMID:15273542).

7. Finlayson EV, Birkmeyer JD. Operative mortality with elective surgery in older adults. Eff Clin Pract 2001;4:172-7.(PMID:11525104).

8. TSI, (2017), Turkey Statistical Institute, seniors with Statistics, 2016, Volume: 24644 http // www.tuik.gov.tr

9. Turrentine FE, Wang $H$, Simpson VB, Jones RS. Surgical risk factors, morbidity, and mortality in elderly patients. J Am CollSurg 2006;203:865-87. (PMID:17116555).

10. Marshall WH, Fahey PJ. Operative complications and mortality in patients over 80 years of age. Arch Surg 1964;88:896-904.(PMID:14120726).
11. Evers B, Townsend C, Thompson J. Organ physiology of aging. SurgClin North Am 1994;74:23-39. (PMID:8108769).

12. Preston SD, Southall AR, Nel M, Das SK. Geriatric surgery is about disease, not age. J R Soc Med 2008;101:409-15.(PMID:18687864).

13. Dharmarajan TS, Unnikrishnan D, Dharmarajan L. Perioperative Medical Management. In: Dharmarajan TS, Norman RA (Eds). Clinical Geriatrics. Boca Raton (FL): Parthenon Publishing Group 2003,pp 115-26

14. Thomas DR, Ritchie CS. Pre-operative assessment of older adults. J Am GeriatrSoc 1995;43:811-21. (PMID:7602039).

15. Leung J, Dzankic S. Relative importance of preoperative healthstatus versus intraoperative factors in predicting post-operative adverse outcomes in geriatric surgical patients. J Am GeriatrSoc 2001;49:1080-5.(PMID:11555070).

16. Rodgers A, Walker N, Schug S, et al. Reduction of post-operative mortality and morbidity with epidural or spinal anaesthesia: Resultsfrom overview of randomised trials. BMJ 2000;321:1-12. (PMID:11118174).

17. Chung JY, Chang WY, Lin TW, et al. An analysis of surgical outcomes in patients aged 80 years and older. Acta Anaesthesiol Taiwan 2014;52:153-8. (PMID: 25446194).

18. Hwang K, Lee JP, Yoo SY, Kim H. Relationships of comorbidities and old age with postoperative complications of head and neck free flaps: a review. J Plast Reconstr Aesthet Surg 2016;69:1627-35.(PMID: 27697538).

19. Fukui K, Fujioka M, Yamasaki K, Yamakawa S, Matsuo H, Noguchi M. Risk factors for postoperative complications among the elderly after plastic surgery procedures performed under general anesthesia. Plast Surg Int 2018; doi.org/10.1155/2018/7053839. (PMID:30112200). 